\title{
Repercussões do novo Código de Ética Médica na prática psiquiátrica
}

\author{
Impacts of the new Brazilian Code of Medical Ethics on psychiatric practice
}

\author{
Luiz Alberto B. Hetem ${ }^{1}$, Rogério Wolf de Aguiar²
}

\begin{abstract}
${ }^{1}$ Vice-presidente, Associação Brasileira de Psiquiatria (2007-2010). Professor, Pós-Graduação em Saúde Mental, Faculdade de Medicina de Ribeirão Preto, Universidade de São Paulo (USP), São Paulo, SP. ${ }^{2}$ Primeiro secretário, Conselho Regional de Medicina do Rio Grande do Sul. Ex-presidente, Associação Brasileira de Psiquiatria (1995-1998). Professor adjunto, Departamento de Psiquiatria e Medicina Legal, Universidade Federal do Rio Grande do Sul (UFRGS), Porto Alegre, RS.
\end{abstract}

A sexta edição do Código de Ética Médica está em vigor desde 13 de abril de 2010. O documento anterior, de 1988, foi revisto pela necessidade de atualização sobre os deveres profissionais levando-se em conta as mudanças sociais e os progressos tecnológicos ocorridos nas duas últimas décadas.

$\mathrm{O}$ resultado do trabalho sério e exaustivo desenvolvido ao longo de 2 anos é muito bom, e os objetivos do projeto foram atingidos. O novo Código de Ética Médica representa um avanço para a sociedade e para os médicos na construção de uma relação responsável e ética.

$\mathrm{O}$ documento é composto de 25 princípios fundamentais, 10 normas diceológicas (sobre os direitos dos médicos), 118 artigos deontológicos (relacionados aos seus deveres) e quatro disposições gerais.

As principais novidades são: o reforço à autonomia do paciente, sem, no entanto, descuidar da do médico; a ênfase na importância crescente dos cuidados paliativos para pacientes em estado terminal ou que apresentem doenças crônicas ou incuráveis; e a ampliação do alcance das normativas, agora abarcando o médico em cargo de gestão, pesquisa e ensino. Há também maior detalhamento das diretrizes relacionadas à publicidade médica, ao conflito de interesses, à solicitação de segunda opinião, à responsabilidade médica, ao uso de placebo em pesquisa e ao envolvimento com planos de financiamento, cartões de desconto ou consórcios para procedimentos médicos. Finalmente, como seria de se esperar num documento dessa importância, estimula-se a cautela na incorporação de novas técnicas em saúde.

O novo Código reitera a vedação da eutanásia, de acordo com a lei brasileira, mas protege a ortotanásia, desestimulando a distanásia. A ortotanásia se refere ao respeito à evolução natural das doenças graves e terminais, desencorajando o uso desnecessário de meios artificiais de prolongamento da vida que não tenham sentido curativo ou aliviador do sofrimento (distanásia).

Outro campo contemporâneo da prática médica abordado pelo novo Código se refere à fertilização assistida e também à genética. Novos desafios éticos provocados pelos grandes progressos da pesquisa nessas áreas foram enfrentados com muita seriedade.

As repercussões dessas novidades para a prática psiquiátrica são positivas. Sem dúvida, contribuirão para sua melhoria e efetividade na medida em que estimulam uma relação médico-paciente mais equilibrada e respeitosa, ao mesmo tempo em que a protegem de interferência externa.

A pesquisa em psicofarmacologia clínica, por outro lado, notadamente a que se ocupa da eficácia e tolerabilidade de novos medicamentos, vai sentir a proibição de ensaios controlados com placebo "quando houver tratamento eficaz e efetivo para a doença pesquisada". Isso porque, sabe-se bem, algumas síndromes psiquiátricas, dentre elas as depressões e alguns transtornos de ansiedade, são susceptíveis a efeito placebo em porcentagem não desprezível. Por isso, a boa intenção de privar alguns pacientes de tratamentos com eficácia já comprovada, mesmo em condições controladas e com acompanhamento de comitê de ética, poderá expor um número ainda maior de pessoas ao uso de medicamentos que não sejam verdadeiramente efetivos no controle de seus males, retardando, com isso, sua recuperação e o avanço da terapêutica psicofarmacológica.

A modernização do Código e sua entrada em vigor também chamaram a atenção da mídia nacional. Houve muitas entrevistas e depoimentos publicados, que certamente têm contribuído para divulgar a seriedade com que a categoria médica, através do sistema conselhal, tem encarado a prática médica e a qualidade ética dos serviços prestados à população.

\footnotetext{
Correspondência:

Rogério Wolf de Aguiar, Av. Lajeado, 505, CEP 90460-110, Porto Alegre, RS. Tel./fax: (51) 3332.1728. E-mail: wolfaguiar@uol.com.br

Os autores declararam que não há conflitos de interesse associados à publicação deste editorial.

Copyright (C) Revista de Psiquiatria do Rio Grande do Sul - APRS
} 